\title{
Characterization of a Unique Bordetella bronchiseptica vB_BbrP_BB8 Bacteriophage and Its Application as an Antibacterial Agent
}

\author{
Mateusz Szymczak ${ }^{1}$, Bartłomiej Grygorcewicz ${ }^{2}{ }^{\circledR}$, Joanna Karczewska-Golec ${ }^{3}$, \\ Przemysław Decewicz ${ }^{3}{ }^{\mathbb{D}}$, Jarosław Adam Pankowski ${ }^{1}$ (D) Hanna Országh-Szturo ${ }^{1}$, \\ Paweł Bącal ${ }^{4,5}$, Barbara Dołęgowska ${ }^{2}$ (D) and Piotr Golec ${ }^{1, *(D)}$ \\ 1 Department of Molecular Virology, Institute of Microbiology, Faculty of Biology, University of Warsaw, \\ Miecznikowa 1, 02-096 Warsaw, Poland; mszymczak@biol.uw.edu.pl (M.S.); \\ jaroslaw.adam.pankowski@biol.uw.edu.pl (J.A.P.); h.szturo@student.uw.edu.pl (H.O.-S.) \\ 2 Department of Laboratory Medicine, Chair of Microbiology, Immunology and Laboratory Medicine, \\ Pomeranian Medical University in Szczecin, Powstancow Wielkopolskich 72, 70-111 Szczecin, Poland; \\ bartlomiej.grygorcewicz@pum.edu.pl (B.G.); barbara.dolegowska@pum.edu.pl (B.D.) \\ 3 Department of Environmental Microbiology and Biotechnology, Institute of Microbiology, Faculty of Biology, \\ University of Warsaw, Miecznikowa 1, 02-096 Warsaw, Poland; karczewska@biol.uw.edu.pl (J.K.-G.); \\ decewicz@biol.uw.edu.pl (P.D.) \\ 4 Nalecz Institute of Biocybernetics and Biomedical Engineering, Polish Academy of Sciences, Ksiecia \\ Trojdena 4, 02-109 Warsaw, Poland; bacal@chem.uw.edu.pl \\ 5 Laboratory of Theory and Applications of Electrodes, Faculty of Chemistry, University of Warsaw, \\ 02-093 Warsaw, Poland \\ * Correspondence: pgolec@biol.uw.edu.pl; Tel.: +48-225-541-414
}

Received: 26 January 2020; Accepted: 17 February 2020; Published: 19 February 2020

\begin{abstract}
Bordetella bronchiseptica, an emerging zoonotic pathogen, infects a broad range of mammalian hosts. B. bronchiseptica-associated atrophic rhinitis incurs substantial losses to the pig breeding industry. The true burden of human disease caused by B. bronchiseptica is unknown, but it has been postulated that some hypervirulent $B$. bronchiseptica isolates may be responsible for undiagnosed respiratory infections in humans. B. bronchiseptica was shown to acquire antibiotic resistance genes from other bacterial genera, especially Escherichia coli. Here, we present a new B. bronchiseptica lytic bacteriophage-vB_BbrP_BB8-of the Podoviridae family, which offers a safe alternative to antibiotic treatment of B. bronchiseptica infections. We explored the phage at the level of genome, physiology, morphology, and infection kinetics. Its therapeutic potential was investigated in biofilms and in an in vivo Galleria mellonella model, both of which mimic the natural environment of infection. The BB8 is a unique phage with a genome structure resembling that of T7-like phages. Its latent period is $75 \pm 5 \mathrm{~min}$ and its burst size is $88 \pm 10$ phages. The BB8 infection causes complete lysis of B. bronchiseptica cultures irrespective of the MOI used. The phage efficiently removes bacterial biofilm and prevents the lethality induced by B. bronchiseptica in G. mellonella honeycomb moth larvae.
\end{abstract}

Keywords: phage therapy; zoonosis; emerging diseases; antibiotic resistance; Galleria mellonella; phage stability; biofilm; animal model; atrophic rhinitis; veterinary microbiology

\section{Introduction}

Bordetella bronchiseptica is a Gram-negative coccobacilli-shaped bacterium capable of colonizing the respiratory track of mammalian hosts, primarily farm, wild, and companion animals [1]. The bacterium is a common etiological agent of tracheobronchitis, conjunctivitis, rhinitis, mandibular 
lymphadenopathy, and pneumonia [2]. Its effect tends to be most prominent in tightly packed areas, such as shelters, households, or intensive piggery systems [2]. Interestingly, dogs suffering from B. bronchiseptica-associated kennel cough can pass the pathogen to cats [3]. Zoonotic transfer to humans is also possible, albeit rarely reported [4]. The majority of the reported cases included immunocompromised individuals, such as transplant recipients, HIV-infected patients or those with a history of malignancy [5-7].

The bacterium spreads via the airborne route to the respiratory ciliated epithelium, often resulting in chronic infections [8]. Bordetella bronchiseptica infection may cause a wide range of symptoms, from a mild illness with fever, cough, sneezing, outflow from conjunctiva and swollen lymph nodes, to severe pneumonia with shortness of breath, cyanosis, and death [9]. Infected pigs often suffer from atrophic rhinitis (AR), a costly respiratory disease greatly affecting livestock production. It manifests itself by the atrophy of the nasal turbinate bones and lung lesions. Microscopic lesions are characterized by mucosal neutrophil infiltration, cilia loss, epithelial metaplasia, and bone resorption with replacement by fibrous tissue. Pulmonary lesions include neutrophil infiltration of the airways, necrosis of the alveoli and blood vessels, hemorrhage, and, eventually, extensive fibrosis [10]. In addition to impaired healing, pigs suffering from AR experience decreased appetite and difficulty with food intake, and consequently show a slower increase of body weight [10]. Importantly, B. bronchiseptica is known for concurrent infections with Pasteurella multocida [11]. In pigs, an infection with B. bronchiseptica alone usually leads to mild, nonprogressive atrophic rhinitis (NPAR). A mixed infection with both B. bronchiseptica and P. multocida results in progressive atrophic rhinitis (PAR) [12]. Whereas dermonecrotic toxin produced by P. multocida is the main factor behind the observed damage in pigs, the presence of $B$. bronchiseptica promotes the rate of nasal cavity colonization by the toxigenic bacterium [13].

Currently, veterinary vaccines are a standard method of preventing B. bronchiseptica-associated diseases in animals. While multiple vaccination methods have been developed, the existence of sufficient duration of immunity is being questioned [14]. Additionally, due to the appearance and dissemination of antibiotic resistant $B$. bronchiseptica strains [15], alternative means of combating B. bronchiseptica infections are required. One report shows a case of woman who suffered from recurring B. bronchiseptica infections, due to bacterial persistence. The relapses occurred despite minocycline treatment [16]. A suggested explanation for the observed persistence was the B. bronchiseptica ability to create biofilm. The formation of biofilm has also been proposed to justify the decreased efficiency of vaccines used against $B$. pertussis - a pathogen closely related to $B$. bronchiseptica [1]. This further underlines the necessity of developing new methods of fighting Bordetella-associated infectious diseases, especially the strategies that could efficiently reduce a threat from biofilm production. With their natural ability to prey on specific strains of bacteria, bacteriophages (phages) have been postulated an efficient solution. Phages active against human pathogenic bacteria have been studied at least since the beginning of the 20th century [17]. Even though B. bronchiseptica species has been known for more than a hundred years, there have only been few reports describing its bacteriophages [18-23].

In this study, we isolated, described the biology of, as well as explored the therapeutic potential of a new B. bronchiseptica bacteriophage vB_BbrP_BB8, further referred to as BB8, which had been isolated from a sewage sludge sample. Beyond the standard characterization and testing, the new phage was evaluated in vivo in a Galleria mellonella model for its ability to kill B. bronchiseptica cells. Not only did the phage prove capable of reducing the viability of bacterial biofilm, it also almost completely eliminated the lethality of infection in the G. mellonella infectious disease model.

\section{Results}

\subsection{Isolation of the BB8 Phage}

The B. bronchiseptica A5 phage host strain-isolated in this study from a chronically diseased companion animal - was identified based on MALDI-TOF mass spectrometry profiling (confidence score of 2.447) and 16S rRNA gene sequencing (GenBank acc. no. MT040725, 100\% identity to $16 \mathrm{~S}$ 
rRNA gene from B. bronchiseptica strain LSBSG1, acc. no. MN082542). The strain displayed natural resistance to cephalosporins (cephalexin, cefuroxime) and amoxicillin/clavulanic acid.

The phage was isolated from an environmental sample with a standard enrichment technique [24] using the above mentioned B. bronchiseptica host strain. The phage was named vB_BbrP_BB8, according to the guideline of Adriaenssens and Brister [25]. In this work, the phage will be further referred to as BB8.

Apart from the BB8 ability to infect B. bronchiseptica we did not observe its efficiency in producing plaques on any other tested organism. During the host range analysis, we investigated more than 20 animal isolates of Klebsiella spp., Acinetobacter spp., Enterobacter cloacae, and Escherichia coli.

The BB8 phage formed clear plaques of approximately $1 \mathrm{~mm}$ in diameter. Over time the plaque size grew to $3 \mathrm{~mm}$ (Figure 1C-E). The presence of a halo zone around plaques suggested release of lytic enzymes during infection.

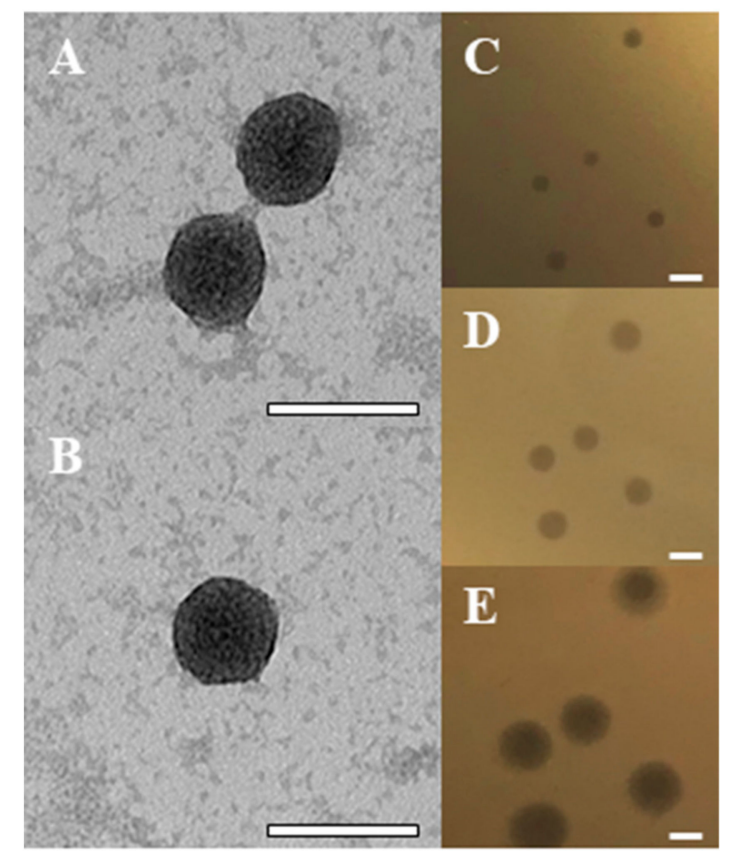

Figure 1. Characteristics of BB8 phage virions and plaques. (A and B) TEM image of BB8 phage virions is typical of the Podoviridae family, Caudovirales order. The scale bars in A and B represent $50 \mathrm{~nm}$. (C-E) The growth of phage plaques over time. Plaque phenotype observed after 8,12 , and $24 \mathrm{~h}$ is presented in panels $\mathbf{C}-\mathbf{E}$, respectively. The scale bars in C-E panels represent $3 \mathrm{~mm}$.

Transmission electron microscopic images revealed a icosahedral virion of approximately $37 \mathrm{~nm}$ in diameter, typical of the Podoviridae family in the order Caudovirales (Figure 1A,B).

\subsection{Phage BB8 Resistance to Physico-Chemical Factors}

To evaluate the phage potential to be used in therapy and other applications, phage activity and stability under the various conditions important from the viewpoint of practical use were determined. The BB8 phage displayed high stability at $\mathrm{pH} 4$ to 8 , but lost it quickly at lower $\mathrm{pH}$ values. In addition, whereas there was no immediate loss of activity after increasing the $\mathrm{pH}$ above 8 , a substantial activity decrease in an alkaline environment was observed over time (Figure 2A). Furthermore, BB8 was sensitive to increased temperature, experiencing a serious decrease in activity over time at $43{ }^{\circ} \mathrm{C}$. Higher temperatures $\left(60-80^{\circ} \mathrm{C}\right)$ resulted in an immediate loss of activity (Figure 2B). It is noteworthy that the phage lysate did not display any losses in stability when stored at $4{ }^{\circ} \mathrm{C}$ for at least 6 months. Furthermore, BB8 proved susceptible to UV radiation (Figure 2C). Within the first minute of exposure, 
almost half of the phage particles lost activity. Within $20 \mathrm{~min}$, the number of active phage particles dropped to a nearly undetectable level.
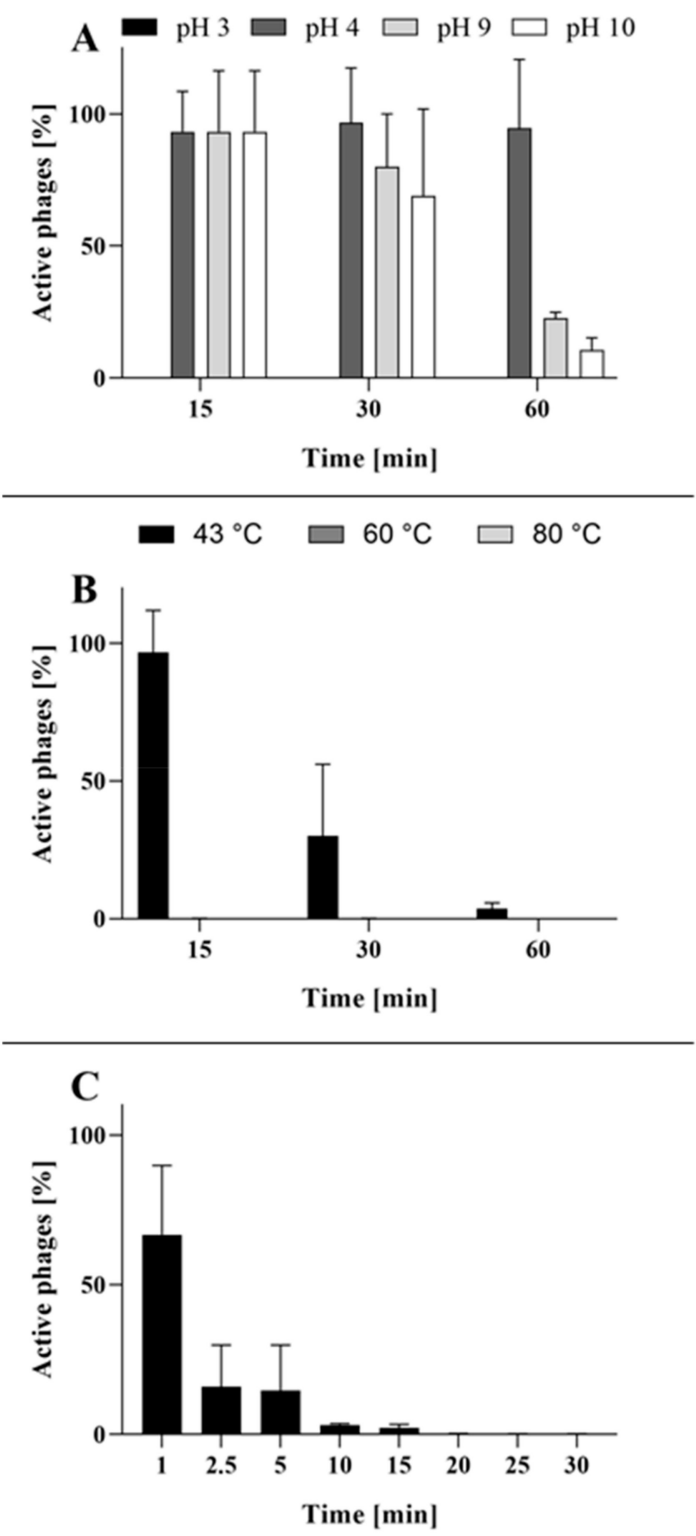

Figure 2. Phage BB8 stability under various conditions. (A) Effect of $\mathrm{pH}$ on the phage activity. The number of active phage particles at $\mathrm{pH} 3$ was below the detection limit (<400 PFU/mL). (B) Effect of temperature on the phage activity. The number of active phage particles at $60^{\circ} \mathrm{C}$ and $80{ }^{\circ} \mathrm{C}$ was below the detection limit $(<400 \mathrm{PFU} / \mathrm{mL})$. (C) Effect of UV radiation on the phage activity. The presented results are average values from three experiments, with SD represented by error bars.

\subsection{Adsorption, One-Step Growth and Collapse Assays}

The phage adsorption to the host cell is the first step towards successful infection and propagation. An adsorption kinetics analysis indicated that approximately $96 \%$ of BB8 particles adsorbed to the surface of B. bronchiseptica cells within the first minute. The value increased to over $99 \%$ after $5 \mathrm{~min}$ (Figure 3A). Efficient adsorption enables a phage to infect a bacterial cell and replicate by hijacking its metabolism. To further explore BB8 development in B. bronchiseptica, a one-step growth assay was employed (Figure 3B). The observed eclipse time was $55 \pm 5 \mathrm{~min}$ and the latency period was $75 \pm 5 \mathrm{~min}$. The yield of phages per infected cell (the burst size) was approximately $88 \pm 10$ phage particles. Additionally, the BB8 phage proved highly efficient in destroying liquid bacterial cultures, 
irrespective of the MOI used. A complete lysis was observed with all MOI variants tested (Figure 3C). While high MOIs could cause the collapse after just $2 \mathrm{~h}$, a much lower MOI showed effects after $4-5 \mathrm{~h}$ (Figure 3C).
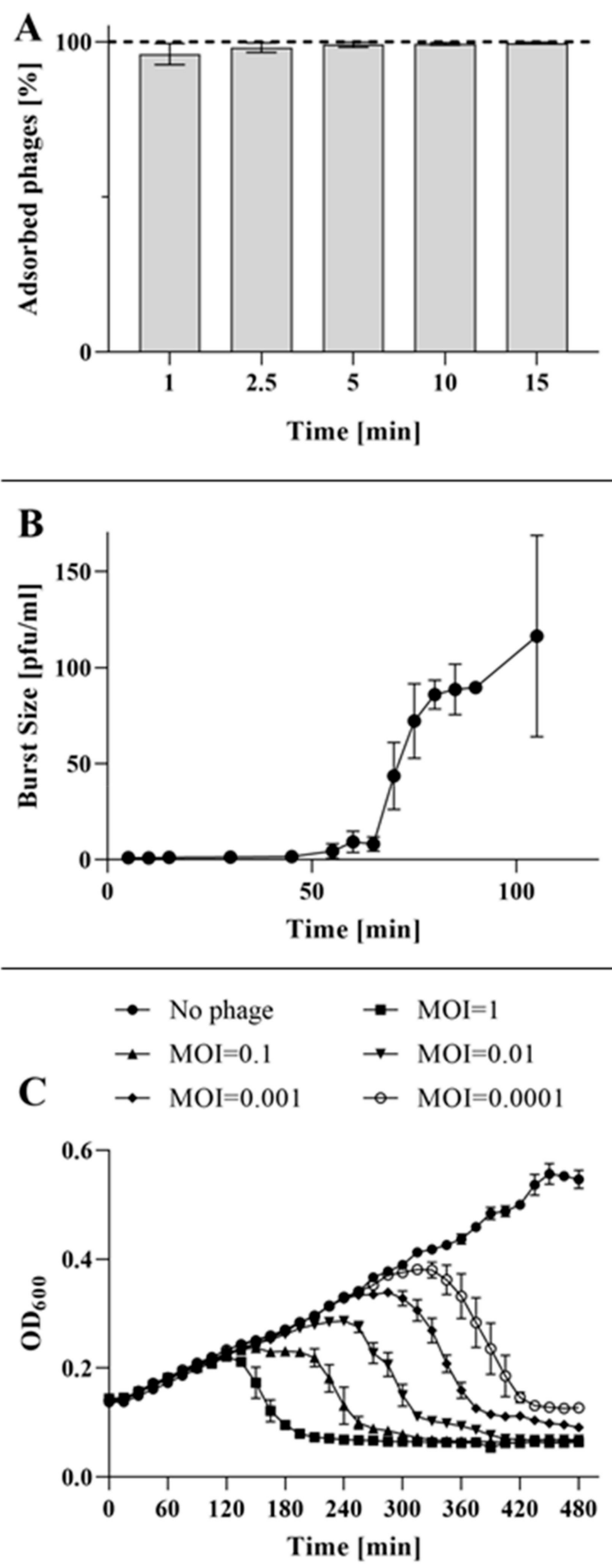

Figure 3. Phage BB8 development. (A) Adsorption of phage particles to the bacterial cells was assessed after 1, 2.5, 5, 10, and $15 \mathrm{~min}$. (B) One-step growth curve shows that the eclipse period was a little under $60 \mathrm{~min}$ while latent period was around $75 \mathrm{~min}$ and resulted in the production of approx. 88 phage particles. (C) Collapse assay of the phage-infected bacterial culture indicated the high efficiency of host cell lysis. Regardless of the MOI used, the bacterial culture was completely lysed by the phage. The presented results are average values from three experiments, with SD represented by error bars. 


\subsection{Phage Genome Exploration}

Therapeutic applications of a phage candidate require an in-depth exploration of the phage genome. The BB8 phage contains dsDNA genome (41,593 bp). The fully annotated sequence of the BB8 phage was deposited in the GenBank database (acc. no. MK984681). The correctness of assembly of the genome sequence was verified through digestion of genomic DNA, isolated from the phage virions, with a series of restriction enzymes and comparison of the resulting pattern with that obtained by in silico digestion of the assembled BB8 genome sequence. The pattern of restriction fragments on an agarose gel image was in line with that in the in silico generated image, thus confirming the determined BB8 sequence (Figure 4).

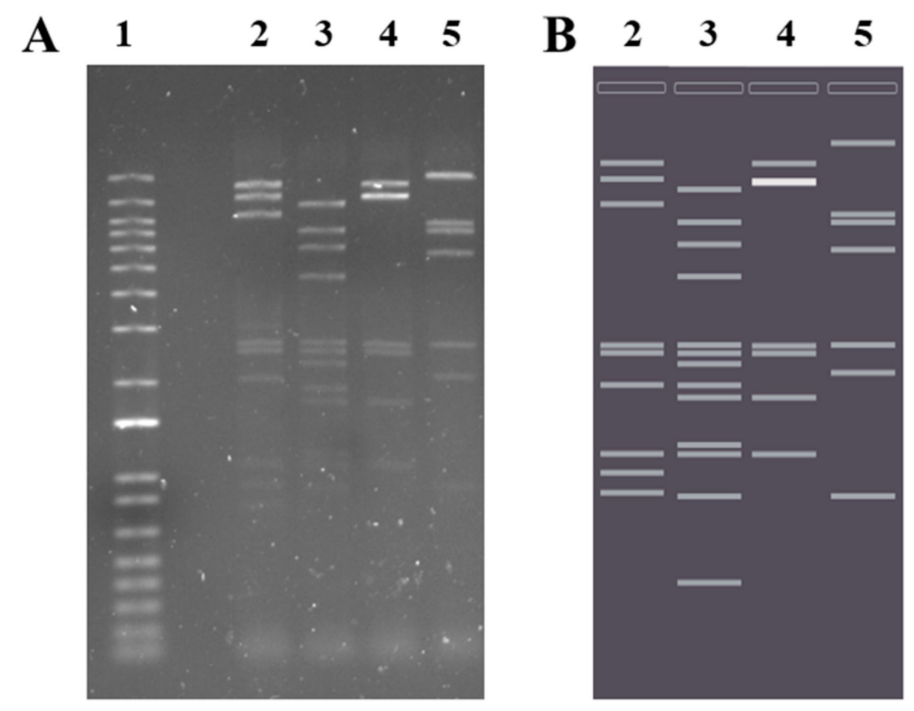

Figure 4. Analysis of restriction patterns of BB8 genome. (A) Electrophoretic gel image of BB8 genomic DNA digested with various restriction enzymes shows the same pattern as (B) in silico prepared electrophoretic gel image of the restriction fragments. Lines: (1) DNA size marker, (2) NcoI + SmaI, (3) $\mathrm{NcoI}+\mathrm{NdeI}$, (4) NcoI, and (5) NdeI.

The genome analysis revealed that BB8 genome possesses a structure similar to that of the T7 lytic phage (Figure 5A). However, the BB8 nucleotide (nt) sequence shared no significant similarities to the sequence of T7, and the BB8 amino acid (aa) sequence showed identity of less than $55 \%$ in a few regions (Figure 5B). Likewise, no similarities to BB8 at either nt or aa sequence levels were found in the other Podoviridae phages capable of infecting B. bronchiseptica (i.e., BMP-1, BIP-1, and BPP-1) (Figure 5B). Interestingly, no gene that could potentially encode RNAP was identified in the nt sequence of any of the three phages. These three phages share a high $(>86 \%)$ level of sequence identity between each other, but display no such relation to T7-like viruses. Furthermore, BB8 itself shows an aa sequence similarity (of up to $85 \%$ in some regions) with two Ralstonia phages (DU-RP-I and RsoP1EGY). Particularly striking is the nt and aa sequences identity of their RNAPs (Figure 5B).

Importantly, we did not identify any genes coding for toxins, components of lysogenic development pathway (with the exception of an integrase gene, a putative relic, discussed below) or any other genes that would disqualify BB8 from therapeutic applications. 

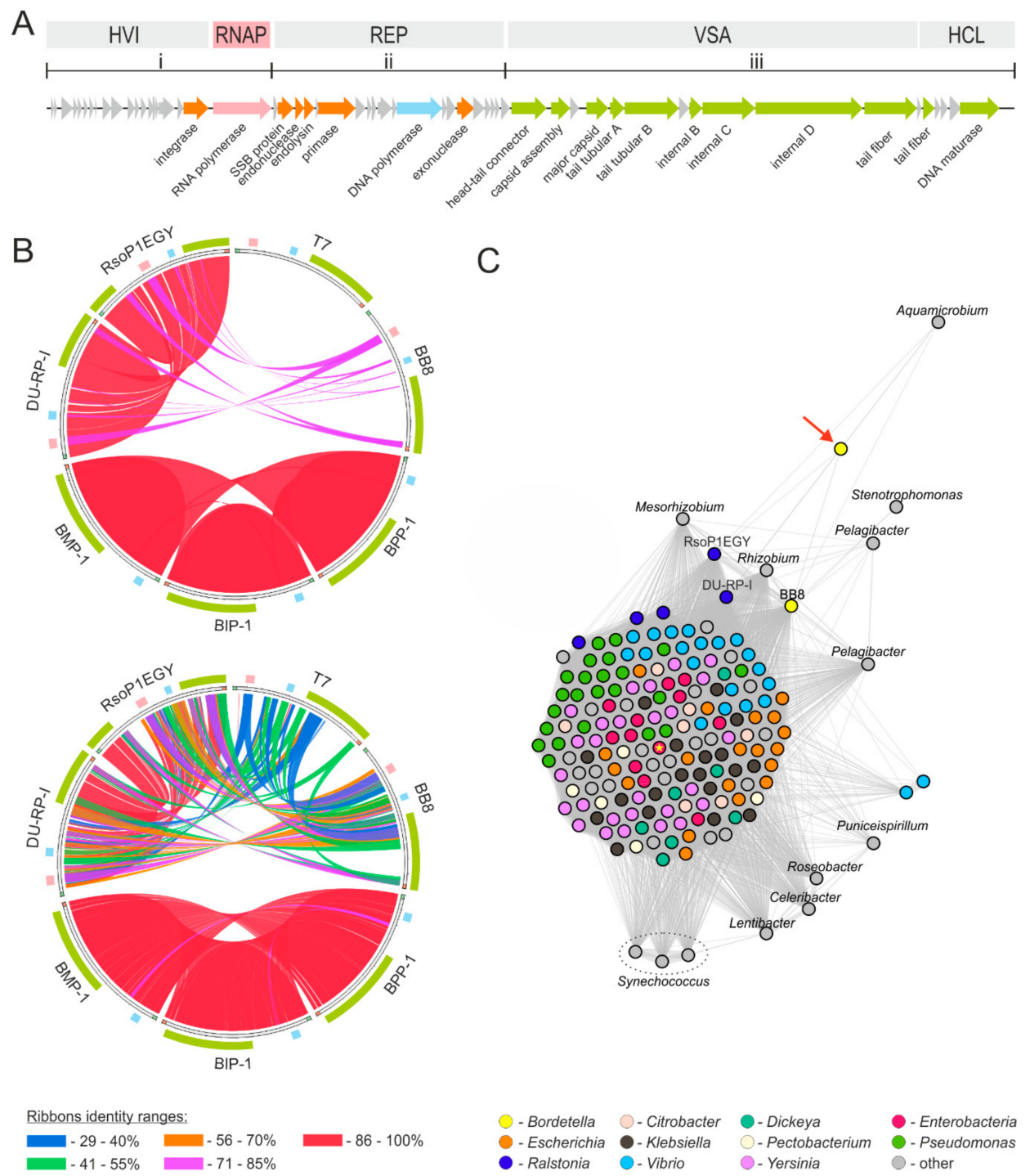

Figure 5. Genome organization and comparative genomics of BB8 phage. (A) Genome organization of BB8. A block at the top shows host-virus interaction (HVI), RNA polymerase (RNAP), DNA replication (REP), virus structure and assembly (VSA) and host cell lysis (HCL) modules, as well as transcription of genes of class i, ii, and iii. The modules were identified and described with the use, and according to, the genome organization of the model phage T7. The arrows below represent open reading frames identified in the BB8 genome and their transcriptional orientation. The coloring scheme of the arrows is as follows: grey-hypothetical proteins with unknown function, orange-proteins with predicted function, pink-RNA polymerase, blue-DNA polymerase, green-virus structure and assembly proteins. (B) The comparison of BB8 sequences with those of T7 phage of Enterobacteria (NC_001604), two most similar Ralstonia phages, i.e., RsoP1EGY (MG711516) and DU-RP-I (MF979559), and all known podoviruses infecting Bordetella, i.e., BMP-1 (AY526908), BIP-1 (AY526909), and BPP-1 (AY029185). The comparison was performed with the Circoletto tool on nucleotide (top graph) and amino acid (bottom graph) sequence levels. The blocks on the outmost ring correspond to the location of RNAP, DNA polymerase, and VSA modules. The colors of these correspond to the colors in panel A. (C) Sequence similarity network of proteins encoded by BB8 and the most closely related bacterial viruses. Each node represents a single phage genome and each edge, and its thickness, reflects the number of similar proteins encoded by two phages above the set thresholds. The coloring is based on the host's family taxonomy. Enterobacteria T7 phage's node is additionally indicated with a yellow star. All viruses within the presented network belong to Podoviridae family except the Bordetella phage vB_BbrM_PHB04 (MF663786) annotated as a member of Siphoviridae family-indicated by the red arrow. 


\subsection{Applicability of BB8 Phage as an Antibacterial Agent}

To evaluate the potential of the BB8 phage to act as a treatment for B. bronchiseptica infections we analyzed its abilities to destroy bacterial biofilm in vitro and to fight $B$. bronchiseptica infection in an in vivo honeycomb moth (G. mellonella) larvae model. The results show that the phage effectively destroys B. bronchiseptica biofilm (Figure 6). An established, 48-h biofilm was treated with BB8 for $4 \mathrm{~h}$, after which there was a statistically significant $(p<0.05)$ reduction in the biofilm viability and biomass (Figure 6A,B). The high efficiency in biofilm viability reduction was observed with all phage concentrations tested (Figure 6A). The viability reduction level reached approx. 92\% when phages in $1 \times 10^{7}$ and $1 \times 10^{5} \mathrm{PFU} / \mathrm{mL}$ concentrations were applied. In the case of $1 \times 10^{3} \mathrm{PFU} / \mathrm{mL}$ phage concentration, viability reduction of around $86 \%$ was observed. Additionally, the treatment resulted in approx. $75 \%, 71 \%$, and $59 \%$ of biofilm biomass reduction for phage concentrations of $1 \times 10^{7}, 1 \times 10^{5}$, and $1 \times 10^{3} \mathrm{PFU} / \mathrm{mL}$, respectively (Figure $6 \mathrm{~B}$ ). To confirm these effects, the bacterial biofilm exposed to BB8 was further analyzed by SEM (Figure 6C-D). A lower number of bacterial cells (compared with a control variant of the biofilm without phage treatment) together with completely lysed cells were visible on the SEM images of B. bronchiseptica biofilm treated with BB8. Moreover, a changed morphology was observed for a number of bacterial cells. The cells were not as round as those in the control biofilm, which suggests that they were dead.

A
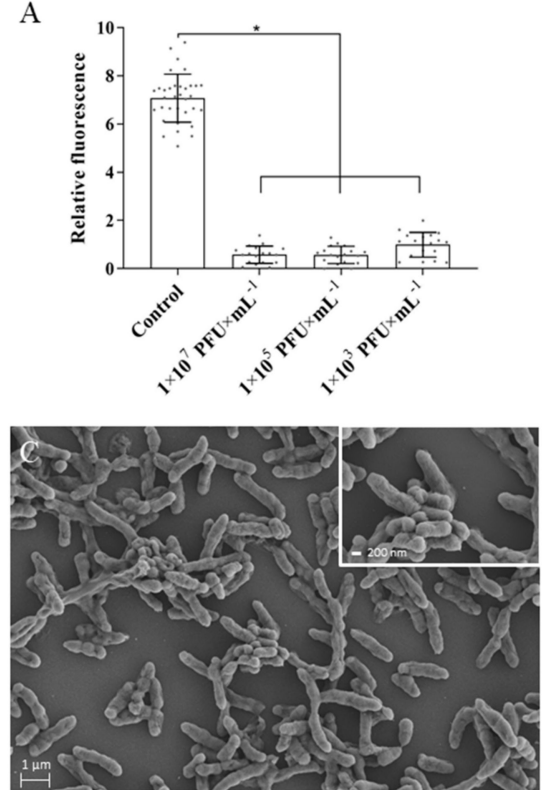

B
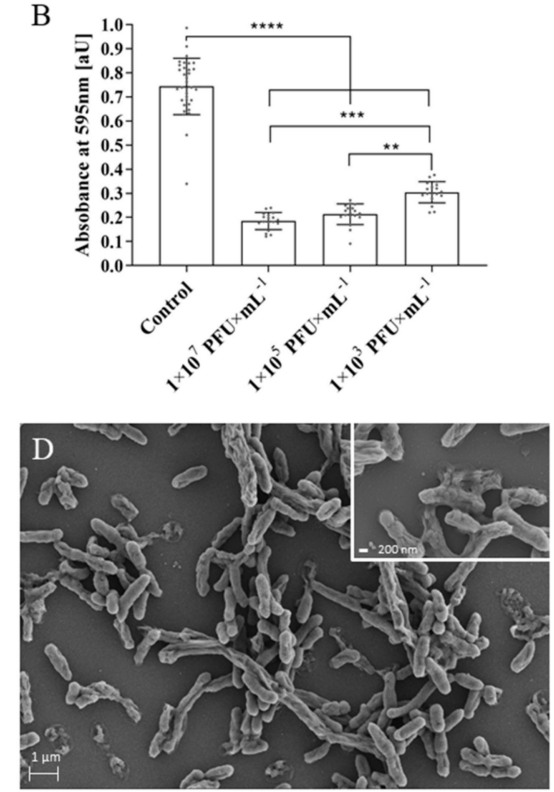

Figure 6. Effect of phage BB8 treatment on B. bronchisepica biofilm. Decrease of (A) viability and (B) mass of $B$. bronchiseptica biofilm after 4-h treatment with BB8 phage in three different concentrations. A B. bronchiseptica biofilm without the addition of BB8 served as a control. Each dot in graphs (A) and (B) represents a biological replicate and the results were analyzed with one-way ANOVA $\left(^{* * * *} p<\right.$ $\left.0.0001 ;{ }^{* * *} p<0.001 ;{ }^{* *} p<0.01 ; * p<0.05\right)$. The SEM images of B. bronchiseptica biofilm untreated and treated with phage $B B 8$ are presented in panels $C$ and $\mathbf{D}$, respectively. Figure insets present untreated (C) and phage-treated (D) biofilms at higher magnification. The scale bars in C and D represent $200 \mathrm{~nm}$.

Experiments on the larvae model infected with B. bronchiseptica showed that BB8 phage treatment can drastically reduce the mortality of the infected organism (Figure 7). First, the most effective lethal dose of bacteria was identified (Figure 7A). Injection with $2.5 \times 10^{7} \mathrm{CFU}$ of B. bronchiseptica per larva (Figure 7A) proved most lethal and was further used in BB8 phage treatment of B. bronchispetica-infected larvae. Approximately $70 \%$ of untreated larvae died within $24 \mathrm{~h}$ after having been injected with the pathogen cells and the entire population was gone after $96 \mathrm{~h}$. Conversely, the phage-treated, B. bronchiseptica-infected larvae displayed only a minimal drop in survivability over the entire 
experiment duration (survivability rate was $\geq 90 \%$ after $96 \mathrm{~h}$ ). Additionally, the injection of buffer alone or the phage suspension alone (control groups) caused no trauma to larvae. Importantly, the presence of the phage in haemocoel caused neither stress symptoms (including melanization) nor larvae mortality.
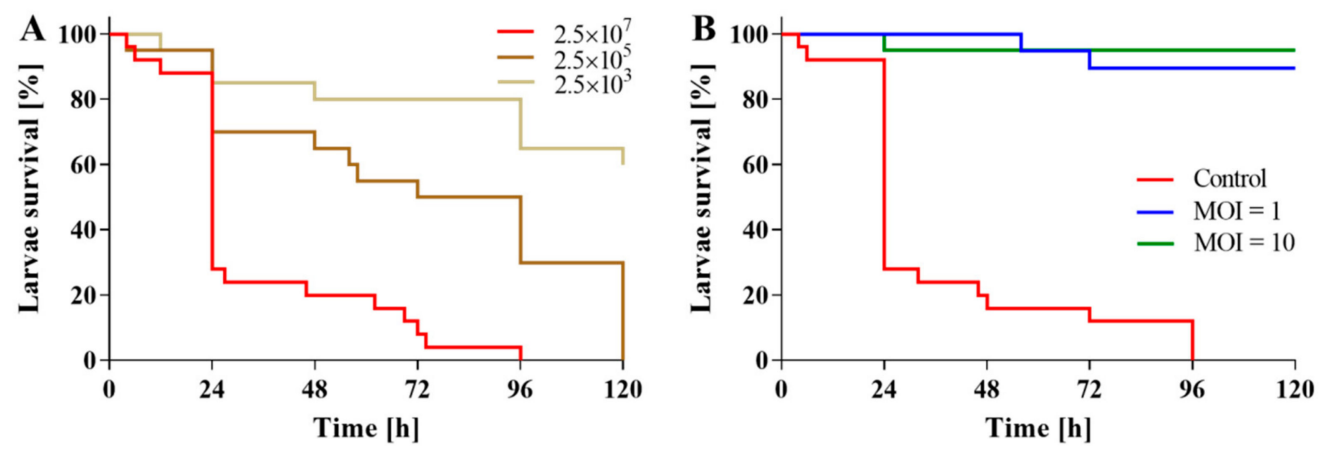

Figure 7. Lethality of honeycomb moth larvae. (A) Influence of B. bronchiseptica cell number on larvae survivability. Twenty-five larvae per group and three groups $\left(2.5 \times 10^{3}, 2.5 \times 10^{5}\right.$, and $\left.2.5 \times 10^{7} \mathrm{CFU} / \mathrm{larva}\right)$ were analyzed. (B) Treatment of B. bronchiseptica-infected G. mellonella larvae with BB8 phage. Control group (red line) includes Galleria larvae after treatment with B. bronchiseptica alone (approx. $2.5 \times 10^{7}$ $\mathrm{CFU})$. Treatment with phage BB8 almost completely abolished the lethality of the infection at MOIs of 1 and 10 (blue and green line, respectively). Twenty-five larvae per group and three groups (control, $\mathrm{MOI}=1$, and $\mathrm{MOI}=10$ ) were analyzed. Survivability in larvae treated with buffer alone or with phage alone was $100 \%$ (these lines were omitted for clarity).

\section{Discussion}

Antibiotic-resistant bacterial infections are a major threat to not only human but also animal health. As recognized by the One Health concept, human and animal health are in fact interconnected through-among other things-the biology and ecology of their shared pathogens. B. bronchiseptica, an emerging zoonotic pathogen, is a common cause of infections among diverse domestic, farm, and wild animals, but is most important and best described in dogs and pigs [2]. In humans the actual burden of diseases caused by B. bronchiseptica is unknown, but it has been postulated that $B$. bronchiseptica infections are more common than previously appreciated, and that some hypervirulent isolates may in fact be responsible for undiagnosed respiratory infections [26]. In humans, the commonly used diagnostic methods that employ PCR-based identification accurately detect $B$. pertussis and B. parapertussis, but not B. bronchiseptica [26].

While $B$. bronchiseptica is generally susceptible to several groups of antibiotics, including tetracyclines, $\beta$-lactams, macrolides, aminoglycosides, and sulphonamides, the effects tend to differ between isolates [26,27]. Aminoglycoside and aminocyclitol, phenicol, fluoroquinolone, $\beta$-lactam, sulfonamide, tetracycline, and trimethoprim resistance mechanisms were described in B. bronchiseptica isolates [15]. Most of the identified antibiotic resistance genes in B. bronchiseptica were located on conjugative plasmids. The rising level of antibiotic resistance in B. bronchiseptica strains combined with the ease of acquiring and transferring resistance genes from and to, other bacterial genera that share the same niches, especially E. coli [15], highlight the need for developing effective treatment strategies against this pathogen other than those based solely on antibiotics.

One promising alternative to antibiotic treatment is phage therapy [17], in which the activity and specificity of bacterial viruses is harnessed to destroy pathogenic bacteria [28]. In this work, we isolated a new phage-BB8-infecting a B. bronchiseptica strain that had been isolated from an animal infection. The phage has a lytic lifestyle, efficiently adsorbs to its host cells and produces a high yield of daughter particles (approx. 90 PFU/IC). Due to these traits, we explored the potential of BB8 as a weapon against $B$. bronchiseptica infections in detail. A substantial reduction of bacterial biofilm viability and biomass were obtained upon exposing it to the phage lysate (approx. $70 \%$ of biofilm 
biomass removal and approx. $90 \%$ biofilm viability reduction). While the ability of phages to reduce the biomass of bacterial biofilms was previously demonstrated in multiple bacterial models [29], this is the first report of $B$. bronchiseptica biofilm removal by a bacteriophage. Phage-mediated biofilm removal may be critically important in therapeutic applications as-according to the National Institutes of Health (NIH) - biofilms are implicated in over $80 \%$ of microbial infections in the body (NIH, 2002). Therapies that aim at biofilm removal are vital in the case of B. bronchiseptica and other pathogens for which biofilm formation is a major virulence factor.

Laboratory conditions are different from those observed in real animal infection sites. Therefore, therapeutic potential of a phage candidate should be evaluated in in vivo models that can mimic the natural environment of an infection. In this study, BB8 phage displayed the ability to almost completely eliminate the lethality of B. bronchiseptica-infected honeycomb moth larvae-an increasingly popular infectious disease model. The larvae immune system is structurally and functionally similar to the innate immune response of mammals. The major advantages to using the insect model are also reduced laboratory animal use, lowered cost, and the ease of manipulation in high containment. Importantly, the results obtained using the insect show strong correlation with those obtained using mice or mammalian cells $[30,31]$. The honeycomb moth larvae infection model was successfully applied in the past for pathogenesis studies, assessment of activity and toxicity of new antimicrobial agents, and for the evaluation of phage therapy. Specifically, the model was used for the assessment of in vivo therapeutic effectiveness of phages against Cronobacter sakazakii, Pseudomonas aeruginosa, Burkholderia cepacia, and Acinetobacter baumannii infections [32-35]. Recently the larvae model has been used along a mouse model of acute pneumonia for the evaluation of phage treatment of carbapenem-resistant Acinetobacter baumannii (CRAB) infections. A single dose of phage B $\phi-\mathrm{R} 2096$ at the very high MOI of 100 increased survival rate of CRAB-infected honeycomb moth larvae from $0 \%$ to $50 \%$ ( $24 \mathrm{~h}$ post CRAB infection). Survival rates of phage-treated, CRAB-infected mice were $30 \%$ (at MOI of 0.1 ) and $100 \%$ (at MOI of 10 ) at day 10 post CRAB infection. Mice in the bacteria-only-treatment group all died by day 5 after infection with CRAB [35].

Melanization of the larvae hemolymph is a marker of the humoral immune responses in $G$. mellonella and is analogous to abscess formation in mammalian infections [36]. The lack of melanization after injection of BB8 phage in this study proved that BB8 did not react with the immune system of G. mellonella larvae. This, together with the other, above-mentioned attributes, makes BB8 a safe therapeutic candidate for combating B. bronchiseptica infections.

Genome analysis of BB8 provided further insight into the nature of this phage. Genes responsible for virus-host interactions, cell lysis, and virus assembly were identified. Genes encoding RNA and DNA polymerases were also found in the BB8 genomic sequence. The presence of an endolysin gene in the BB8 genome explains the formation of a halo zone around BB8 plaques, as the encoded enzyme degrades bacterial cell wall [37]. Another interesting feature is the presence of a potential integrase gene. Identification of the gene was based on the presence of multiple integrase or tyrosine site-specific recombinase domains (e.g., cd00796 or COG4974 with e-values of 2.31e-33 and 1.48e-09, respectively) as well as sequence homology to Enterobacteria phage lambda integrase (1Z1B_A—100\% HHpred probability). The BB8 seems to be a strictly lytic phage, as it produced only clear plaques and completely lysed the host culture irrespective of MOI used for infection, culture OD (from 0.2 to 0.6 ), or temperature $\left(30\right.$ and $37^{\circ} \mathrm{C}$ ). Therefore, the presence of a potential integrase gene could be explained as an evolutionary relic or an element acquired through horizontal gene transfer. Additionally, no other gene encoding DNA-binding protein—a potential repressor-was identified.

Despite having the overall genome structure typical of T7-like phages, BB8 displays no significant similarity to $\mathrm{T} 7$ at the level of genomic sequence. However, it shows similarity (of less than $40 \%$ ) of its RNAP amino acid sequence to that of the enzyme found in T7-like viruses. Other Podoviridae phages known to infect $B$. bronchiseptica form a separate group, even less similar to T7 at the level of their nt and aa sequences (possible similarity of less than $20 \%$ ), and are characterized by the lack of genes encoding RNAP. Overall, BB8 shares the highest amino acid sequence similarity ( $85 \%$ in the most similar regions) 
with Ralstonia phages. The Ralstonia spp. are mainly known as plant pathogens [38], but they can also act as opportunistic human pathogens [39]. Importantly, neither the in silico analysis of the high-quality whole genome sequence nor the phage development assays showed in BB8 a functional lysogenic lifestyle, virulence factors, toxins, resistance genes, or transducible elements, thus indicating the safety of the phage for therapeutic applications.

\section{Materials and Methods}

\subsection{Sample Origin}

The strain of B. bronchiseptica was isolated on March 06, 2014 from a nasal swab obtained from a 4-year-old, male Belgian hare (Oryctolagus cuniculus) with a chronic rhinorrhea (runny nose), in the course of routine treatment. The BB8 phage was isolated from a wastewater sample collected from a sewage treatment plant in Wołomin (Wołomin County, Masovian Voivodship, Poland) on August 25, 2018 according to [24].

\subsection{Bacterial Host and Culture Conditions}

The identity of the bacterial strain as B. bronchiseptica was determined with the use of MALDI-TOF profiling (MALDI Biotyper system, Bruker Daltonik GmbH, Bremen, Germany) and sequencing of the 16S rRNA gene (primer sequences: 27F 5'-AGAGTTTGATCMTGGCTCAG-3' and 1492R 5'-GGTTACCTTGTTACGACTT-3') by commercial services. LB, LB-agar, top-agar (LB medium with the addition of $0.7 \%$ of agar) and Brain Heart Infusion (BHI) media (Merck KGaA, Darmstadt, Germany) were used for cultivation of B. bronchiseptica at $37^{\circ} \mathrm{C}$.

\subsection{Phage Isolation}

Phage isolation was performed according to [24]. After the isolation, three rounds of propagation from an individual phage plaque were carried out to prepare a lysate of the pure phage strain.

\subsection{Phage Propagation and Purification}

Phage BB8 was propagated in a B. bronchiseptica liquid culture. The culture was infected during the exponential growth phase $\left(\mathrm{OD}_{600}=0.2-0.5\right)$ with one phage plaque or with the phage lysate to reach the multiplicity of infection $(\mathrm{MOI})=0.01$. After the phage addition, the culture was incubated with shaking at $37^{\circ} \mathrm{C}$ until complete lysis of bacteria was observed. Phage lysate was then centrifuged (8000 g, $10 \mathrm{~min}$, room temperature). The number of plaque forming units (PFUs) was determined by a standard plaque technique, as described previously [40]. Briefly, double-layer LB agar plates with an overnight culture of B. bronchiseptica in top agar were used and $2.5 \mu \mathrm{L}$ of phage lysate serial dilutions was spotted onto a bacterial lawn. Plates were incubated at $37^{\circ} \mathrm{C}$ and plaques were counted after $16 \mathrm{~h}$.

\subsection{Thermal and $p H$ Stability of the Phage}

For pH stability testing, $10 \mu \mathrm{L}$ of the phage lysate $\left(1 \times 10^{10} \mathrm{PFU} / \mathrm{mL}\right)$ was mixed with $990 \mu \mathrm{L} \mathrm{LB}$ broth in a series of tubes, each with a different $\mathrm{pH}$ (adjusted using $\mathrm{NaOH}$ or $\mathrm{HCl}$ ), and incubated for 10, 30, or $60 \mathrm{~min}$ at room temperature (RT). For temperature stability testing, $10 \mu \mathrm{L}$ of the phage lysate $\left(1 \times 10^{10} \mathrm{PFU} / \mathrm{mL}\right)$ was mixed with $990 \mu \mathrm{L}$ of LB broth in a series of tubes, and the samples were incubated at 43,60 , or $80^{\circ} \mathrm{C}$ for 15,30 , or $60 \mathrm{~min}$. At each of these time points, the number of phages (plaque forming units, PFUs) was calculated. Control phage samples were incubated at $\mathrm{pH} 7$ and RT, respectively.

\subsection{Phage Resistance to UV Light}

For UV resistance testing, $10 \mu \mathrm{L}$ of the phage lysate $\left(1 \times 10^{10} \mathrm{PFU} / \mathrm{mL}\right)$ was mixed with $990 \mu \mathrm{L}$ of LB broth. The mixture was then spotted onto a polystyrene Petri dish and exposed to UV-C light (UVC lamp, Philips TUV-30-W-245 nm Lamp, type No. 57413-P/40, Philips co., Warszawa, Poland) from a 
distance of $65 \mathrm{~cm}$ for 1, 2.5, 5, 10, 15, 25, and $30 \mathrm{~min}$. A control sample was incubated on a laboratory bench at RT.

\subsection{Transmission Electron Microscopy (TEM)}

Transmission electron microscopic images of phage virions were obtained using TEM LIBRA 120 (Carl Zeiss NTS GmbH, Oberkochen, Germany) microscope (HT $=120$ kV, LaB6 cathode). Samples were prepared by applying a droplet of phage suspension to thin, carbon-coated copper grids (400 mesh), followed by immersing the grids in $1 \%$ uranyl acetate for contrasting. Then, the samples were left to dry at RT.

\subsection{Adsorption Kinetics}

The adsorption assay was conducted as described previously [40]. Briefly, $1 \mathrm{~mL}$ of an overnight B. bronchiseptica culture was spiked with $10 \mu \mathrm{L}$ of the phage suspension to reach $\mathrm{MOI}=0.1$. The mixture was incubated at $37^{\circ} \mathrm{C}$. After $1,2.5,5,10$, and $15 \mathrm{~min}, 100-\mu \mathrm{L}$ aliquots were withdrawn and centrifuged (5000 g, $1 \mathrm{~min}, \mathrm{RT}$ ) to deposit the phage-adsorbed cells as sediment. The titer of the remaining free phages was determined by supernatant titration on double-layer agar plates. The initial number of phages ( $100 \%$ of the phages used) was determined by adding an appropriate volume of the BB8 phage lysate to a medium without bacteria, followed by titration. The number of adsorbed phages was determined as a decrease in PFUs in the supernatant relative to the initial number of phages.

\subsection{One-Step Growth Curve}

For one-step growth analysis, $25 \mathrm{~mL}$ of LB medium was inoculated with an overnight culture of B. bronchiseptica $(50: 1, v / v)$. The culture was grown until $\mathrm{OD}_{600}=0.2$ and then infected with the phage at MOI $=0.1$ and incubated at $37^{\circ} \mathrm{C}$ for $1 \mathrm{~min}$ (theoretically $96 \%$ of phages should have adsorbed). Then, $25 \mu \mathrm{L}$ of infected cells was transferred to $25 \mathrm{~mL}$ of fresh LB broth and incubated at $37^{\circ} \mathrm{C}$ with shaking (150 rpm). At appropriate timepoints, $300 \mu \mathrm{L}$ and $300 \mu \mathrm{L}$ of samples treated with $300 \mu \mathrm{L}$ of chloroform were individually collected for PFUs calculations. The samples for estimation of the number of infection centers (ICs) were analyzed as described previously [41].

\subsection{Bacterial Culture Collapse}

For the host culture collapse studies, an overnight culture of bacteria was refreshed in LB medium and allowed to grow until reaching $\mathrm{OD}_{600}$ of 0.2. Then each, culture was infected with the phage at MOIs ranging from 0.0001 to 1 . The $\mathrm{OD}_{600}$ measurement was made every 15 min till the lysis of bacterial culture was observed. Measurements were carried out with the use of Sunrise absorbance microplate reader and Magellan v 6.62009 software (Tecan Trading AG, Männedorf, Switzerland).

\subsection{Biofilm Formation and Assessment of Phage Lytic Activity in Biofilm}

The B. bronchiseptica biofilm formation protocol was adapted from [42] with minor modifications. Briefly, overnight cultures of B. bronchiseptica were diluted 1:100 into fresh BHI medium and $200 \mu \mathrm{L}$ of a culture per well was transferred to 96-well polystyrene microtiter plates and incubated without agitation at $37^{\circ} \mathrm{C}$ for $48 \mathrm{~h}$ with medium change every $6 \mathrm{~h}$. Post incubation, wells were washed with PBS buffer to remove planktonic and unattached cells. Established biofilm was treated with phage suspensions (final concentration of approx. $1 \times 10^{7}, 1 \times 10^{5}$, and $1 \times 10^{3} \mathrm{PFU} / \mathrm{mL}$ ) in BHI medium and incubated for $4 \mathrm{~h}$ at $37^{\circ} \mathrm{C}$. After phage treatment, cell viability and biomass in biofilm were measured using resazurin and crystal violet staining assays according to [43] with minor modifications. The PBS-washed wells containing B. bronchiseptica biofilm were filled with $200 \mu \mathrm{L}$ of a fresh BHI medium containing $20 \mathrm{mM}$ of resazurin and incubated for $40 \mathrm{~min}$ at $37^{\circ} \mathrm{C}$ with shaking (100 rpm). After incubation, the medium was transferred for fluorescence $(\lambda \mathrm{ex}=520 \mathrm{~nm} ; \lambda \mathrm{em}=590 \mathrm{~nm})$ measurement. Biofilm was washed using PBS and fixed with ethanol for biomass quantification. Then ethanol was removed and plates 
were air dried. Staining was conducted by the addition of crystal violet $(1 \% w / v)$ and incubation for $20 \mathrm{~min}$ at RT. Stained biofilm was washed and $200 \mu \mathrm{L}$ of ethanol:acetone $(8: 2, v / v)$ solution was added to each well for decolorization. The biofilm was then quantified by determining the optical density of the resulting solution at $595 \mathrm{~nm}$. All of the spectrometric measurements were carried out with the use of EnVision 2105 multimode plate reader (PerkinElmer, Waltham, MA, USA).

\subsection{Scanning Electron Microscopy (SEM)}

Visualization of biofilms was carried out by scanning electron microscopy (SEM), as described before [44]. Biofilms were fixed for $24 \mathrm{~h}$ in $0.1 \mathrm{M}$ cacodylate buffer ( $\mathrm{pH} 7.3$ ) with $3 \%$ glutaraldehyde followed by washing for 60 min with cacodylate buffer without glutaraldehyde, and then four times for $30 \mathrm{~min}$ with the fresh buffer, followed by dehydration for $6 \mathrm{~h}$ in $96 \%$ ethanol. Biofilms were air-dried and coated with gold-palladium ( $2-4 \mathrm{~nm}$ thick) and analyzed at nanometer image resolution by MERLIN SEM (Carl Zeiss NTS GmbH, Oberkochen, Germany) at accelerating voltages in the range of $2-5 \mathrm{kV}$.

\subsection{In Vivo Assessment of Phage Activity in B. bronchiseptica-Infected Galleria mellonella Larvae}

The in vivo test on G. mellonella larvae was performed as described previously [45] with minor modifications. Briefly, to assess B. bronchiseptica pathogenicity, larvae were infected with three different dose of bacteria $\left(2.5 \times 10^{3}, 2.5 \times 10^{5}\right.$ and $2.5 \times 10^{7} \mathrm{CFU} /$ larva), by an injection of $5 \mu \mathrm{L}$ dose into the larval hemolymph behind the last proleg and incubated at $37^{\circ} \mathrm{C}$ for $120 \mathrm{~h}$. To evaluate the bacteriophage activity, $2.5 \times 10^{7} \mathrm{CFU} /$ larva bacterial dose was chosen. Larvae were infected with $B$. bronchiseptica by an injection $5 \mu \mathrm{L}$ dose into the larval hemolymph behind the last proleg. After $20 \mathrm{~min}$, the treated larvae received the bacteriophage suspension at $\mathrm{MOI}=1$ or $\mathrm{MOI}=10$, which was injected $(5 \mu \mathrm{L})$ into the opposite side to the bacterial infection site. Injections with a buffer control and phage suspension control were also carried out in control larvae groups to assess the negative impact of an injection and the phage toxicity. Larvae were incubated at $37^{\circ} \mathrm{C}$ for $96 \mathrm{~h}$. The larvae of a dark color that did not respond to physical contact were marked as deceased.

\subsection{Phage DNA Extraction and Restriction Enzyme Digestion}

Phage DNA was isolated with the use of Genomic mini AX Phage kit (A\&A Biotechnology, Gdynia, Poland). For restriction analysis, the phage DNA was digested with the following single FastDigest enzymes: $\mathrm{NcoI}$ and NdeI or with the following enzyme combinations: $\mathrm{NcoI}+\mathrm{SmaI}$ and $\mathrm{NcoI}+\mathrm{NdeI}$. Enzymes and buffers were obtained from Thermo Fisher Scientific (Waltham, MA, USA). Restriction digest was performed in accordance with the manufacturer's protocols. Restriction fragments were analyzed on $1 \%$ agarose gel and stained with ethidium bromide.

\subsection{Whole Genome Sequencing (WGS)}

The complete nucleotide sequence of the BB8 phage was determined in the DNA Sequencing and Oligonucleotide Synthesis Laboratory (oligo.pl) at the Institute of Biochemistry and Biophysics, Polish Academy of Sciences (Warsaw, Poland). The phage genome was sequenced on an Illumina MiSeq platform in a paired-end mode with a v3 chemistry kit. The sequence reads obtained were filtered for quality and assembled using Newbler v3.0 software (Roche, Basel, Switzerland).

\subsection{Bioinformatics}

The annotation of BB8 genome was carried out manually with Artemis software [46]. Gene calling was performed using PHANOTATE with tRNAScan-SE [47,48]. The functional annotation of encoded proteins was based on homology searches performed using BLAST programs [49] against NCBI protein non-redundant or virus databases. Moreover, the identification of protein domains was performed with CD-Search and HHpred tools [50,51]. 
The comparative genomic analysis of BB8 was performed with Circoletto tool [52] and the construction of a sequence similarity network. The following thresholds were applied with the Circoletto tool: e-value of 1e-30 when comparing nucleotide sequences of phage genomes, and e-value of $1 \mathrm{e}-10$ and query coverage of HSP of at least $75 \%$ when comparing predicted proteomes of analyzed phages. The construction of a similarity network was based on all-against-all BLASTp comparison of BB8 with all 10,362 bacterial viruses available at NCBI (as of February 01, 2019). During the BLASTp search, e-value of $1 \mathrm{e}-10$, query coverage of $\mathrm{HSP}$ of at least $75 \%$, and at least $50 \%$ of sequence identity thresholds were applied. The results were then parsed using Python script and visualized as a network on which each node represents a phage genome and each edge, and its thickness, correspond to the number of proteins shared between two phages above the set thresholds. The networks were visualized in Gephi 0.9.2 using ForceAtlas 2 layout [53,54].

The in silico electrophoretic gel image was prepared with the use of SnapGene Viewer 3.2.1 software (GSL Biotech, Chicago, IL, USA; available at snapgene.com).

\subsection{Statistical Analysis}

The biofilm assay data were analyzed with one-way ANOVA. Results were considered statistically significant at a $p$ value of $<0.05$. The Kaplan-Meier survival curves for the G. mellonella model were prepared. All statistical analyses were carried out using GraphPad Prism 5.02 (Graph Pad Software, San Diego, CA, USA).

\section{Conclusions}

In conclusion, a new phage infecting B. bronchiseptica was isolated and characterized. We demonstrated its effective development in host cells not only under the standard laboratory conditions, but also in a bacterial biofilm and in an in vivo animal infection model. Importantly, the in vivo study revealed no mortality or side effects in the phage-treated honeycomb moth larvae group. The genome analysis of BB8 revealed that it is a unique phage with no sequence similarity to other known Bordetella phages. Taken together, the results of an in vitro, in vivo and in silico integrated approach indicated that phage BB8 is a safe and effective treatment alternative to the standard, antibiotic-based therapies of B. bronchiseptica infections, which—based on current knowledge-are probably more common than previously thought, with some hypervirulent isolates responsible for undiagnosed respiratory infections also in humans [26].

Author Contributions: Conceptualization, J.K.-G., P.D. and P.G.; Data curation, M.S., B.G., P.D., J.K.-G. and P.G.; Formal analysis, B.G., P.D., J.K.-G. and P.G.; Funding acquisition, P.G.; Investigation, M.S., B.G., P.D., J.P., H.O.-S., P.B. and P.G.; Methodology, B.G., J.K.-G., P.D. and P.G.; Project administration, P.G.; Resources, B.D. and P.G.; Software, P.D.; Supervision, P.G.; Visualization, M.S., B.G., P.D., J.A.P., P.B. and P.G.; Writing-original draft, B.G., J.K.-G., P.D., J.A.P. and P.G.; Writing-review and editing, J.K.-G. and P.G. All authors have read and agreed to the published version of the manuscript.

Funding: This research was funded by the National Science Centre (Poland) within the project grant no. 2016/23/B/NZ6/02537 and the National Center for Research and Development (Poland) within project grant LIDER/006/414/L-4/12/NCBR/2013 (to P.G.). The APC was funded by University of Warsaw (Poland).

Acknowledgments: We would like to thank Agnieszka Markowska-Zagrajek for her assistance with phage BB8 isolation.

Conflicts of Interest: The authors declare no conflict of interest. The funders had no role in the design of the study; in the collection, analyses, or interpretation of data; in the writing of the manuscript, or in the decision to publish the results.

\section{Abbreviations}

$\begin{array}{ll}\text { ANOVA } & \text { Analysis of variance } \\ \text { BHI } & \text { Brain heart infusion } \\ \text { CFU } & \text { Colony forming unit } \\ \text { CRAB } & \text { Carbapenem resistant Acinetobacter baumannii }\end{array}$




$\begin{array}{ll}\text { HSP } & \text { High scoring pair } \\ \text { IC } & \text { Infection center } \\ \text { LB } & \text { Lysogeny Broth } \\ \text { MALDI } & \text { Matrix-assisted laser desorption/ionization } \\ \text { MOI } & \text { Multiplicity of infection } \\ \text { NCBI } & \text { National Center for Biotechnology Information } \\ \text { PCR } & \text { Polymerase chain reaction } \\ \text { PFU } & \text { Plaque forming units } \\ \text { RNAP } & \text { RNA Polymerase } \\ \text { RT } & \text { Room temperature } \\ \text { SD } & \text { Standard deviation } \\ \text { SEM } & \text { Scanning electron microscopy } \\ \text { TOF } & \text { Time-of-flight }\end{array}$

\section{References}

1. Cattelan, N.; Dubey, P.; Arnal, L.; Yantorno, O.M.; Deora, R. Bordetella biofilms: A lifestyle leading to persistent infections. Pathog. Dis. 2016, 74, ftv108. [CrossRef]

2. Datz, C. Bordetella Infections in Dogs and Cats: Pathogenesis, Clinical Signs, and Diagnosis. Compend. Contin. Educ. Pract. Vet. N. Am. Ed. 2003, 25, 896-901.

3. Dawson, S.; Jones, D.; McCracken, C.M.; Gaskell, R.M.; Hart, C.A.; Gaskell, C.J. Bordetella bronchiseptica infection in cats following contact with infected dogs. Vet. Rec. 2000, 146, 46-48. [CrossRef] [PubMed]

4. Chomel, B.B. Emerging and Re-emerging zoonoses of dogs and cats. Animals 2014, 4, 434-445. [CrossRef] [PubMed]

5. Ner, Z.; Ross, L.A.; Horn, M.V.; Keens, T.G.; MacLaughlin, E.F.; Starnes, V.A.; Woo, M.S. Bordetella bronchiseptica infection in pediatric lung transplant recipients. Pediatr. Transplant. 2003, 7, 413-417. [CrossRef]

6. Wernli, D.; Emonet, S.; Schrenzel, J.; Harbarth, S. Evaluation of eight cases of confirmed Bordetella bronchiseptica infection and colonization over a 15-year period. Clin. Microbiol. Infect. 2011, 17, 201-203. [CrossRef]

7. Monti, M.; Diano, D.; Allegrini, F.; Delmonte, A.; Fausti, V.; Cravero, P.; Marcantognini, G.; Frassineti, G.L. Bordetella bronchiseptica pneumonia in a patient with lung cancer; a case report of a rare infection. BMC Infect. Dis. 2017, 17, 644. [CrossRef]

8. Trainor, E.A.; Nicholson, T.L.; Merkel, T.J. Bordetella pertussis transmission. Pathog. Dis. 2015, 73, ftv068. [CrossRef]

9. Egberink, H.; Addie, D.; Belák, S.; Boucraut-Baralon, C.; Frymus, T.; Gruffydd-Jones, T.; Hartmann, K.; Hosie, M.J.; Lloret, A.; Lutz, H.; et al. Bordetella Bronchiseptica Infection in Cats: ABCD Guidelines on Prevention and Management. J. Feline Med. Surg. 2009, 11, 610-614. [CrossRef]

10. Brockmeier, S.L.; Register, K.B.; Magyar, T.; Lax, A.J.; Pullinger, G.D.; Kunkle, R.A. Role of the dermonecrotic toxin of Bordetella bronchiseptica in the pathogenesis of respiratory disease in swine. Infect. Immun. 2002, 70, 481-490. [CrossRef]

11. Kureljušić, B.; Weissenbacher-Lang, C.; Nedorost, N.; Stixenberger, D.; Weissenböck, H. Association between Pneumocystis spp. and co-infections with Bordetella bronchiseptica, Mycoplasma hyopneumoniae and Pasteurella multocida in Austrian pigs with pneumonia. Vet. J. 2016, 207, 177-179. [CrossRef] [PubMed]

12. Stepniewska, K.; Markowska-Daniel, I. Occurrence of genes encoding virulence factors in Bordetella bronchiseptica strains isolated from infected and healthy pigs. Bull. Vet. Inst. Pulawy 2012, 56, 483-487. [CrossRef]

13. Chanter, N.; Magyar, T.; Rutter, J.M. Interactions between Bordetella bronchiseptica and toxigenic Pasteurella multocida in atrophic rhinitis of pigs. Res. Vet. Sci. 1989, 47, 48-53. [CrossRef]

14. Ellis, J.A. How well do vaccines for Bordetella bronchiseptica work in dogs? A critical review of the literature 1977-2014. Vet. J. 2015, 204, 5-16. [CrossRef] [PubMed]

15. Kadlec, K.; Schwarz, S. Antimicrobial Resistance in Bordetella bronchiseptica. Microbiol. Spectr. $2018,6$. [CrossRef]

16. Gueirard, P.; Weber, C.; Le Coustumier, A.; Guiso, N. Human Bordetella bronchiseptica infection related to contact with infected animals: Persistence of bacteria in host. J. Clin. Microbiol. 1995, 33, 2002-2006. [CrossRef] 
17. Cisek, A.A.; Dabrowska, I.; Gregorczyk, K.P.; Wyżewski, Z. Phage Therapy in Bacterial Infections Treatment: One Hundred Years After the Discovery of Bacteriophages. Curr. Microbiol. 2017, 74, 277-283. [CrossRef]

18. Petrovic, A.; Kostanjsek, R.; Rakhely, G.; Knezevic, P. The First Siphoviridae Family Bacteriophages Infecting Bordetella bronchiseptica Isolated from Environment. Microb. Ecol. 2017, 73, 368-377. [CrossRef]

19. Liu, M.; Deora, R.; Doulatov, S.R.; Gingery, M.; Eiserling, F.A.; Preston, A.; Maskell, D.J.; Simons, R.W.; Cotter, P.A.; Parkhill, J.; et al. Reverse transcriptase-mediated tropism switching in Bordetella bacteriophage. Science 2002, 295, 2091-2094. [CrossRef]

20. Joo, J.; Gunny, M.; Cases, M.; Hudson, P.; Albert, R.; Harvill, E. Bacteriophage-mediated competition in Bordetella bacteria. Proc. R. Soc. B Biol. Sci. 2006, 273, 1843-1848. [CrossRef]

21. Rauch, H.C.; Pickett, M.J. Bordetella bronchiseptica bacteriophage. Can. J. Microbiol. 1961, 7, 125-133. [CrossRef] [PubMed]

22. Holzmayer, T.A.; Karataev, G.I.; Rozinov, M.N.; Moskvina, I.L.; Shumakov, Y.L.; Motin, V.L.; Mebel, S.M.; Gershanovich, V.N.; Lapaeva, I.A. Bacteriophages of Bordetella sp.: Features of lysogeny and conversion. Zentralbl. Bakteriol. Mikrobiol. Hyg. A 1988, 269, 147-155. [CrossRef]

23. Chen, Y.; Yang, L.; Sun, E.; Song, J.; Wu, B. Characterisation of a newly detected bacteriophage infecting Bordetella bronchiseptica in swine. Arch. Virol. 2019, 164, 33-40. [CrossRef] [PubMed]

24. Twest, R.; Kropinski, A.M. Bacteriophage Enrichment from Water and Soil. In Bacteriophages. Methods in Molecular Biology ${ }^{\mathrm{TM}}$; Clokie, M.R., Kropinski, A.M., Eds.; Humana Press: Totowa, NJ, USA, 2009; pp. $15-21$.

25. Adriaenssens, E.M.; Rodney Brister, J. How to Name and Classify Your Phage: An Informal Guide. Viruses 2017, 9, 70. [CrossRef] [PubMed]

26. Ahuja, U.; Liu, M.; Tomida, S.; Park, J.; Souda, P.; Whitelegge, J.; Li, H.; Harvill, E.T.; Parkhill, J.; Miller, J.F. Phenotypic and genomic analysis of hypervirulent human-associated Bordetella bronchiseptica. BMC Microbiol. 2012, 12, 167. [CrossRef]

27. Speakman, A.J.; Dawson, S.; Corkill, J.E.; Binns, S.H.; Hart, C.A.; Gaskell, R.M. Antibiotic susceptibility of canine Bordetella bronchiseptica isolates. Vet. Microbiol. 2000, 71, 193-200. [CrossRef]

28. Kropinski, A.M. Bacteriophage research-What we have learnt and what still needs to be addressed. Res. Microbiol. 2018, 169, 481-487. [CrossRef]

29. Hansen, M.F.; Svenningsen, S.L.; Røder, H.L.; Middelboe, M.; Burmølle, M. Big Impact of the Tiny: Bacteriophage-Bacteria Interactions in Biofilms. Trends Microbiol. 2019, 27, 739-752. [CrossRef]

30. Brennan, M.; Thomas, D.Y.; Whiteway, M.; Kavanagh, K. Correlation between virulence of Candida albicans mutants in mice and Galleria mellonella larvae. FEMS Immunol. Med. Microbiol. 2002, 34, 153-157. [CrossRef]

31. Maguire, R.; Duggan, O.; Kavanagh, K. Evaluation of Galleria mellonella larvae as an in vivo model for assessing the relative toxicity of food preservative agents. Cell Biol. Toxicol. 2016, 32, 209-216. [CrossRef]

32. Seed, K.D.; Dennis, J.J. Experimental bacteriophage therapy increases survival of Galleria mellonella larvae infected with clinically relevant strains of the Burkholderia cepacia complex. Antimicrob. Agents Chemother. 2009, 53, 2205-2208. [CrossRef] [PubMed]

33. Abbasifar, R.; Kropinski, A.M.; Sabour, P.M.; Chambers, J.R.; MacKinnon, J.; Malig, T.; Griffiths, M.W. Efficiency of bacteriophage therapy against Cronobacter sakazakii in Galleria mellonella (greater wax moth) larvae. Arch. Virol. 2014, 159, 2253-2261. [CrossRef] [PubMed]

34. Beeton, M.L.L.; Alves, D.R.R.; Enright, M.C.C.; Jenkins, A.T.A.T.A. Assessing phage therapy against Pseudomonas aeruginosa using a Galleria mellonella infection model. Int. J. Antimicrob. Agents 2015, 46, 196-200. [CrossRef] [PubMed]

35. Jeon, J.; Park, J.H.; Yong, D. Efficacy of bacteriophage treatment against carbapenem-resistant Acinetobacter baumannii in Galleria mellonella larvae and a mouse model of acute pneumonia. BMC Microbiol. 2019, 19, 70. [CrossRef]

36. Tsai, C.J.Y.; Loh, J.M.S.; Proft, T. Galleria mellonella infection models for the study of bacterial diseases and for antimicrobial drug testing. Virulence 2016, 7, 214-229. [CrossRef]

37. Drulis-Kawa, Z.; Majkowska-Skrobek, G.; Maciejewska, B. Bacteriophages and phage-derived proteins-Application approaches. Curr. Med. Chem. 2015, 22, 1757-1773. [CrossRef]

38. Peeters, N.; Guidot, A.; Vailleau, F.; Valls, M. Ralstonia solanacearum, a widespread bacterial plant pathogen in the post-genomic era. Mol. Plant. Pathol. 2013, 14, 651-662. [CrossRef]

39. Sharma, D.; Sharma, P.; Soni, P.; Gupta, B. Ralstonia picketti neonatal sepsis: A case report. BMC Res. Notes 2017, 10, 28. [CrossRef] 
40. Golec, P.; Karczewska-Golec, J.; Loś, M.; Wegrzyn, G. Bacteriophage T4 can produce progeny virions in extremely slowly growing Escherichia coli host: Comparison of a mathematical model with the experimental data. FEMS Microbiol. Lett. 2014, 351, 156-161. [CrossRef]

41. Golec, P.; Karczewska-Golec, J.; Voigt, B.; Albrecht, D.; Schweder, T.; Hecker, M.; Wȩgrzyn, G.; Łoś, M. Proteomic profiles and kinetics of development of bacteriophage T4 and its ri and riii mutants in slowly growing Escherichia coli. J. Gen. Virol. 2013, 94, 896-905. [CrossRef]

42. Latimer, J.; Forbes, S.; McBain, A.J. Attenuated virulence and biofilm formation in Staphylococcus aureus following sublethal exposure to triclosan. Antimicrob. Agents Chemother. 2012, 56, 3092-3100. [CrossRef] [PubMed]

43. Skogman, M.E.; Vuorela, P.M.; Fallarero, A. Combining biofilm matrix measurements with biomass and viability assays in susceptibility assessments of antimicrobials against Staphylococcus aureus biofilms. J. Antibiot. (Tokyo) 2012, 65, 453-459. [CrossRef] [PubMed]

44. Kwiatek, A.; Bacal, P.; Wasiluk, A.; Trybunko, A.; Adamczyk-Poplawska, M. The dam replacing gene product enhances Neisseria gonorrhoeae FA1090 viability and biofilm formation. Front. Microbiol. 2014, 5, 712. [CrossRef] [PubMed]

45. Olszak, T.; Zarnowiec, P.; Kaca, W.; Danis-Wlodarczyk, K.; Augustyniak, D.; Drevinek, P.; de Soyza, A.; McClean, S.; Drulis-Kawa, Z. In vitro and in vivo antibacterial activity of environmental bacteriophages against Pseudomonas aeruginosa strains from cystic fibrosis patients. Appl. Microbiol. Biotechnol. 2015, 99, 6021-6033. [CrossRef] [PubMed]

46. Carver, T.; Berriman, M.; Tivey, A.; Patel, C.; Böhme, U.; Barrell, B.G.; Parkhill, J.; Rajandream, M.A. Artemis and ACT: Viewing, annotating and comparing sequences stored in a relational database. Bioinformatics 2008, 24, 2672-2676. [CrossRef]

47. Mcnair, K.; Zhou, C.; Dinsdale, E.A.; Souza, B.; Edwards, R.A.; Hancock, J. PHANOTATE: A novel approach to gene identification in phage genomes. Bioinformatics 2019, 35, 4537-4542. [CrossRef]

48. Lowe, T.M.; Eddy, S.R. tRNAscan-SE: A Program for Improved Detection of Transfer RNA Genes in Genomic Sequence. Nucleic Acids Res. 1997, 25, 955-964. [CrossRef]

49. Altschul, S.F.; Madden, T.L.; Schäffer, A.A.; Zhang, J.; Zhang, Z.; Miller, W.; Lipman, D.J. Gapped BLAST and PSI-BLAST: A new generation of protein database search programs. Nucleic Acids Res. 1997, 25, 3389-3402. [CrossRef]

50. Marchler-Bauer, A.; Bo, Y.; Han, L.; He, J.; Lanczycki, C.J.; Lu, S.; Chitsaz, F.; Derbyshire, M.K.; Geer, R.C.; Gonzales, N.R.; et al. CDD/SPARCLE: Functional classification of proteins via subfamily domain architectures. Nucleic Acids Res. 2017, 45, D200-D203. [CrossRef]

51. Söding, J.; Biegert, A.; Lupas, A.N. The HHpred interactive server for protein homology detection and structure prediction. Nucleic Acids Res. 2005, 33, 244. [CrossRef]

52. Darzentas, N. Circoletto: Visualizing sequence similarity with Circos. Bioinformatics 2010, 26, $2620-2621$. [CrossRef] [PubMed]

53. Bastian, M.; Heymann, S.; Jacomy, M. Gephi: An open source software for exploring and manipulating networks. In Proceedings of the International AAAI Conference on Weblogs and Social Media, San Jose, CA, USA, 17-20 May 2009; pp. 361-362.

54. Jacomy, M.; Venturini, T.; Heymann, S.; Bastian, M. ForceAtlas2, a continuous graph layout algorithm for handy network visualization designed for the Gephi software. PLoS ONE 2014, 9, e98679. [CrossRef] [PubMed]

(C) 2020 by the authors. Licensee MDPI, Basel, Switzerland. This article is an open access article distributed under the terms and conditions of the Creative Commons Attribution (CC BY) license (http://creativecommons.org/licenses/by/4.0/). 